\title{
A MODEL FOR THE ANALYSIS OF CONCRETE DAMS DUE TO ENVIRONMENTAL THERMAL EFFECTS
}

\author{
by L. AGULLO, E. MIRAMBELL, A. AGUADO (*)
}

\begin{abstract}
In this article, an analytical model is presented for the simulation of the thermal behavior of dams that are subjected to the environmental thermal action during service. The method of solution adopted as well as the evaluation of the different parameters is described in detail. Also, the theoretical results that are predicted by the model are compared with experimental results obtained through the monitoring of temperature in severaldams in Spain. The dams considered are currently in use, of different types and in distinct locations.
\end{abstract}

( ) Technical University of Catalonia

School of Civil Engineering 
c/ Gran Capitán s/n. Módulo C1

08034 Barcelona. Spain

\section{1.- INTRODUCTION}

The concrete dam in service is permanently subjected to thermal action due to its environment. The character of the action, which is associated with the meteorological conditions and the conditions of the reservoir water, dictates the inclusion of all the specific aspects involved.

The numerical model is based on an explicit finite difference scheme that proportions the temperature in the nodes of the mesh at any instant. This is a simple model which considers the presence of different variables that characterize the concrete, the geometry, the dam location and the thermal environment.

\section{2.- ADOPTED HYPOTHESES}

The differential equation for heat conduction in concrete dams during service is expressed by the relation:

$$
\nabla^{2} T=\frac{p \cdot c}{k} \cdot \frac{\partial T}{\partial t}
$$

where:
$\mathrm{T}:$ temperature
$\mathrm{t}$ : time
D: density
c : specific heat
$\mathrm{k}$ : thermal conductivity

In the analysis the following assumptions have been made for the concrete medium: continuous, isotropic, homogeneous and permanence of the thermal properties.

Also, it is supposed that the internal heat generation during the setting and hardening processes has ended, and in consequence, the relative term representing the heat generated for unit time and unit volume disappears. 
In addition, it is assumed that the heat flux in the transversal section is predominantly unidirectional along the thickness; this hypothesis has also been adopted in other relevant studies [Stucky and Derron (1957), Townsend (1965), ACI (1987)]. This permits the analysis of the transversal section through the separate analysis of the levels corresponding to different heights with thickness as a principal variable (Fig. $1)$.

Fig. 1.- Model of the analysis of the transversal section

\section{Initial condition}

The initial condition for the solution of the differential equation (1) is defined by the temperature in the integration domain at a specific instant that is adopted as the time origin.

$$
T(x, z, t)=T_{i}(x, z)
$$

\section{Boundary conditions}

These conditions represent mathematically the different mechanisms of heat transmission between the dam and its surroundings (upstream and downstream).

In the downstream face, the condition of imposed flux is adopted. This condition represents the heat transfer by the various mechanisms of heat transmission (solar radiation, convection, re-radiation).

$$
k \cdot \frac{\partial T}{\partial n}(X, z, t)+q(X, z, t)=0
$$

The thermal energy (q) transferred across the downstream face is the sum of the energies due to the solar radiation, $\mathrm{q}_{\mathrm{s}}$, convection, $\mathrm{q}_{\mathrm{c}}$, and re-radiation, $\mathrm{q}_{\mathrm{r}}$.

$$
q(x, z, t)=q_{s}(x, z, t)+q_{e}(x, z, t)+q_{z}(x, z, t)
$$

The heat due to the solar radiation (short-wave radiation) can be expressed though the relation 


$$
q_{t}(x, z, t)=a \cdot I(X, z, t)
$$

where I is the total solar radiation that is incident on the surface at the instant $\mathrm{t}$ and a is the absorptivity of the concrete.

The heat lost or gained by the surfaces due to convection is defined by Newton's law

$$
q_{e}(x, z, t)=h_{e} \cdot\left[T(X, z, t)-T_{e}(t)\right]
$$

In the above equation, $h_{c}$ is the coefficient of heat transfer by convection that is principally a function of the wind velocity, $\mathrm{T}$ is the temperature of the surface at instant $t$, and $\mathrm{T}_{\mathrm{a}}$ is the ambient temperature at that same instant.

The transferred heat due to the thermalre-radiation (short wave radiation) it is modeled through the Stefan-Boltzmann law, written in a quasi-linear form:

$q_{x}(X, z, t)=h_{ \pm}(X, z, t) \cdot\left[T(X, z, t)-T_{ \pm}(t)\right]$

where $h_{r}$ is the coefficient of heat transfer by radiation that depends on the surface temperatures and can be defined by the relation

$$
\begin{aligned}
& h_{ \pm}(X, z, t)=C_{S B} \cdot \cdot\left[\left[\left(T(X, z, t)+T^{*}\right)^{2}\right]+\right. \\
& \left.\left.+\left(T_{\&}(t)+T^{*}\right)^{2}\right] \cdot T(X, z, t)+T_{a}(t)+2 T^{*}\right]
\end{aligned}
$$

In this expression $\mathrm{C}_{\mathrm{SB}}$ is the Stefan-Boltzmann constant, $\mathrm{e}$ is the emissivity of the concrete surface and $\mathrm{T}^{*}$ is a constant that permits the change from Celsius to Kelvin scales.

Therefore, the boundary condition that is imposed on the downstream face can be expressed through the following equation:

$$
\begin{gathered}
k \cdot \frac{\partial T}{\partial n}(X, z, t)+a \cdot I(X, z, t)+h_{c} \cdot\left[T(X, z, t)-T_{a}(t)\right]+ \\
+h_{ \pm}(X, z, t) \cdot\left[T(X, z, t)-T_{a}(t)\right]=0
\end{gathered}
$$


On the upstream face, the boundary condition is that of an imposed temperature; that is, the condition supposes that the temperature $\mathrm{T}$ is known at all points of the surface, at all instants $\mathrm{t}$. The temperature imposed is that of the water in the reservoir.

$$
T(X, z, t)=T_{z 2}(X, z, t)
$$

The boundary condition imposed on the upstream face, in the real case, represents a situation of full reservoir. If the reservoir is empty ( upstream face in direct contact with air) this boundary condition must be replaced by one of imposed flux, as shown in equation 6 .

Consequently, it is possible to solve the equation for the phenomenon of heat conduction in concrete dams in service.

\section{3.- NUMERICAL SOLUTION}

The method of solution is based on an explicit finite difference scheme. The integration domain is discretized as a unidimensional mesh. The finite difference in partial derivatives are determined at the nodes of mesh by the expressions:

$$
\begin{gathered}
\left.\frac{\partial^{2} T}{\partial x^{2}}\right|_{I}=\frac{T_{i+1}-2 T_{I}+T_{ \pm-1}}{(\Delta x)^{2}} \\
\left.\frac{\partial T}{\partial t}\right|_{1}=\frac{T_{1, \Delta t}-T_{1}}{\Delta t}
\end{gathered}
$$

Substituting (11) and (12) in the equation (1) one obtains the following relation

$$
T_{1, \Delta t}=T_{ \pm}+\frac{k}{p \cdot c} \cdot \frac{\Delta t}{(\Delta x)^{2}} \cdot\left[T_{1+1}-2 T_{1}+T_{ \pm-1}\right]
$$


which easily permits the calculation of the temperature at the node $i$, at the instant $(t+) t)$, as a function of the temperatures of node $i$ and the adjacent nodes at the instant $t$.

The necessary and sufficient condition for obtaining a stable solution is the same as the condition that is necessary and sufficient for the convergence of the solution. This condition can be expressed by means of the following expression

$$
\frac{k}{p \cdot c} \cdot \frac{\Delta t}{(\Delta x)^{2}} \leq \frac{1}{2}
$$

However, the above condition does not ensure the stability of the solution at the exterior nodes where the boundary conditions of solar radiation, thermal radiation and convection are imposed.

Establishing the energy balance at the exterior node (i),

$a \cdot I+k \cdot \frac{\left(T_{i+1}-T_{1}\right)}{\Delta x}-h \cdot\left(T_{i}-T_{i}\right)=\rho \cdot c \cdot \frac{\Delta x}{2} \cdot\left(\frac{T_{1, \Delta t}-T_{i}}{\Delta t}\right)$

one obtains

$$
\begin{gathered}
T_{i, \Delta t}=\frac{2 \Delta t}{(\Delta x)^{2}} \cdot \delta \cdot T_{i+1}+\left[1-2 \delta \cdot \Delta t \cdot\left(\frac{1}{(\Delta x)^{2}}+\frac{h}{k \cdot \Delta x}\right)\right] \cdot T_{1}+ \\
+\frac{2 \Delta t}{\Delta x} \cdot \frac{\delta}{k} \cdot\left[a \cdot I+h \cdot T_{d}\right]
\end{gathered}
$$

where

$$
\delta=\frac{k}{p \cdot c}
$$

Supposing that I and $\mathrm{T}_{\mathrm{a}}$ are exact values, and the error in the temperature of the nodes for the instant $\mathrm{t}$ is known, the error at a later instant $\mathrm{t}+$ ) $\mathrm{t}$ can be obtained through the following expression

$$
\Delta t_{i, \Delta t}=\frac{2 \Delta t}{(\Delta x)^{2}} \cdot \delta \cdot \Delta T_{i+1}+\left[1-2 \delta \cdot \Delta t \cdot\left(\frac{1}{(\Delta x)^{2}}+\frac{h}{k \cdot \Delta x}\right)\right] \cdot \Delta T_{i}
$$


Adopting,

$$
n=\max \left(\left|\Delta T_{i+1}\right|,\left|\Delta T_{i}\right|\right)
$$

it has to be verified that

$$
\Delta T_{1, \Delta t} \leq\left[\frac{2 \Delta t \cdot \delta}{(\Delta x)^{2}}+\left|1-2 \delta \cdot \Delta t\left(\frac{1}{(\Delta x)^{2}}+\frac{h}{k \Delta x}\right)\right|\right] \cdot n
$$

The condition of stability requires

$$
\Delta T_{i, \Delta t} \leq n
$$

which can also be written as

$$
\frac{2 \Delta t \cdot \delta}{(\Delta x)^{2}}+\left|1-2 \delta \cdot \Delta t \cdot\left(\frac{1}{(\Delta x)^{2}}+\frac{h}{k \cdot \Delta x}\right)\right| \leq 1
$$

Thus, the following two conditions can be obtained

$$
\begin{gathered}
\frac{2 \delta \cdot \Delta t}{(\Delta x)^{2}}+1-\frac{2 \delta \cdot \Delta t}{(\Delta x)^{2}}+\frac{2 \delta \cdot h \cdot \Delta t}{k \cdot \Delta x} \leq 1 \\
\frac{2 \delta \cdot \Delta t}{(\Delta x)^{2}}-1+2 \delta \cdot \Delta t\left(\frac{1}{(\Delta x)^{2}}+\frac{h}{k \cdot \Delta x}\right) \leq 1
\end{gathered}
$$

From the first one, it follows that ) thas to be positive. From the second, one obtains the value of ) $t$ that yields a stable solution:

$$
\Delta t \leq \frac{1}{\delta\left(\frac{2}{(\Delta x)^{2}}+\frac{h}{k \Delta x}\right)}
$$

which is more restrictive than that obtained previously (Eqn. 14) for the interior nodes. 
The imposed restriction on the time step in this explicit scheme is avoided in implicit methods that are unconditionally convergent and stable, in which the equations to be solved are as many as the nodes in the discretization. In the case of concrete dams, a large number of nodes are needed to reflect adequately the transmission of the heat in the interior which leads to a large number of computational operations like the inversion of a higher order matrix at every time step. For this reason, it is better to employ explicit methods for these cases [Zienkiewicz (1980)].

On the other hand, the use of small time steps permits the close monitoring of the evolution of the temperatures attained in the concrete and of the thermal action of its environment.

\section{4.- EVALUATION AND IMPLEMENTATION OF ENVIRONMENTAL PARAMETERS}

\section{1.- Solar radiation on the dam faces}

In absence of actual measurements of the local solar radiation, the data that is commonly used pertain to the monthly average of the daily global solar radiation on a horizontal surface $\left(\mathrm{H}_{\mathrm{o}}\right)$. The present model obtains the incident solar radiation on the dam faces following the procedure described later.

Using the monthly average $H_{0}$, the method proposed by Liu and Jordan [1963, 1967] permits the calculation of the daily diffused radiation on the surfaces $\mathrm{H}_{\mathrm{d}}$, by obtaining the direct component of the radiation, $\mathrm{H}_{b}$, as the difference between the two. The relation between $\mathrm{H}_{0}$ and $\mathrm{H}_{\mathrm{d}}$ it is expressed by

$$
H_{d}=H_{0} \cdot\left(1.39-4.027 K_{T}+5.531 K_{T}^{2}-3.108 K_{I}^{3}\right)
$$

in which $\mathrm{K}_{\mathrm{T}}$ is the index of the average monthly cloudiness, defined by the ratio between $\mathrm{H}_{0}$ and the monthly average of the extraterrestrial solar radiation $\left(\mathrm{H}_{\mathrm{e}}\right)$.

$$
K_{T}=\frac{H_{0}}{F_{a}}
$$

The extraterrestrial solar radiation can be evaluated through the expression

$$
H_{a}=\frac{24}{\pi} r^{2} \cdot I_{s c}\left(\cos \delta \cos \phi \sin h_{s}+h_{s} \sin \delta \cos \phi\right)
$$


where $\mathrm{r}^{2}$ is the correction factor of the solar constant for every day of the year

$$
r^{2}=1+0.003 \cos \left(\frac{360 z}{365}\right) \quad 1 \leq z \leq 365
$$

$\mathrm{I}_{\mathrm{SC}}: \quad$ solar constant; $\mathrm{I}_{\mathrm{SC}}=4870.8 \mathrm{KJ} / \mathrm{hm}^{2}$

$\mathrm{N}: \quad$ latitude of the location

* : solar declination

$\mathrm{h}_{\mathrm{s}}$ : $\quad$ absolute value of the hourly angle corresponding to sunset, expressed in radians.

The declination can be obtained from tables or approximate formulas that express the declination as a function of the day of the year [for example, Duffie and Beckman (1974)].

Nevertheless, in order to calculate the declination, a representative day is normally obtained for every month. This representative day is usually taken to be that when the extraterrestrial radiation is closest to the value of the average daily extraterrestrial radiation during the given month. In table 1 , after Coronas et al. (1982), the representative day for every month and the corresponding value of the solar declination are presented.

\begin{tabular}{||l|c|c||}
\hline Month & Middle day & (degrees) \\
\hline January & 17 & -20.7 \\
February & 15 & -12.6 \\
March & 16 & -1.7 \\
April & 15 & 9.8 \\
May & 15 & 18.9 \\
June & 10 & 23.0 \\
July & 17 & 21.2 \\
August & 17 & 13.4 \\
September & 16 & 2.6 \\
October & 16 & -8.9 \\
November & 15 & -18.5 \\
December & 11 & -23.0 \\
\hline \hline
\end{tabular}


Table 1.- Middle days and their solar declination.

The hourly angle $\left(h_{s}\right)$ corresponding to sunset is obtained from

$$
\cos h_{t}=-\operatorname{tg} \phi \cdot \operatorname{tg} \delta
$$

where $-h_{s}$ is the hourly angle that corresponds to sunrise.

Knowing the hourly angles of sunrise and sunset, the duration of the solar day (TSV) can be determined. This duration is the time between two consecutive passes of the sun over the longitude of the location. The relation between TSV (in hours) and the hourly angle (in degrees) is given by

$$
h=15(T S V-12)
$$

and consequently, the beginning $\left(\mathrm{TSV}_{\mathrm{i}}\right)$ and the end $\left(\mathrm{TSV}_{\mathrm{f}}\right)$ of the solar day, as well as the duration $\left(\mathrm{TSV}_{\mathrm{o}}\right)$ are defined through the relations

$$
\begin{gathered}
T s V_{1}=12-\frac{1}{15} \arccos (-\operatorname{tg} \phi \cdot \operatorname{tg} \delta) \\
T s V_{ \pm}=12-\frac{1}{15} \arccos (-\operatorname{tg} \phi \cdot \operatorname{tg} \delta) \\
T S V_{0}=\frac{2}{15} \arccos (-\operatorname{tg} \phi \cdot \operatorname{tg} \delta)
\end{gathered}
$$

These relations depend only on the location of the dam $(\mathrm{N})$ and the day of the year $\left.{ }^{*}\right)$; therefore, for a given dam, the interval of solar radiation at its location can be determined. Outside this interval, the incident solar radiation is taken to be zero.

The direct component of the radiation is obtained as mentioned previously: 


$$
H_{b}=H_{\Delta}-H_{d}
$$

Once the direct and diffuse components of the monthly average of the daily global radiation at the location (horizontal plane) have been determined, we get the hourly radiation at different times during the interval that corresponds to sunrise and sunset at the location of the dam. 
The hourly radiations, global and diffuse, are obtained by the relations

$$
\begin{aligned}
& H_{k_{\theta} \Delta}=r_{t} \cdot H_{\Delta} \\
& H_{k_{b} \Delta}=r_{\Delta} \cdot H_{\Delta}
\end{aligned}
$$

where factors $r_{t}$ and $r_{d}$ depend essentially on the hour and duration of the day, and can be evaluated analytically from the expressions

$$
\begin{aligned}
r_{a}\left(h, h_{s}\right)=\frac{\pi}{24} \cdot \frac{\cos h-\cos h_{s}}{\operatorname{sen} h_{s}-h_{s} \cdot \cos h_{s}} \\
r_{t}\left(h, h_{s}\right)=\frac{\pi}{24} \cdot(a+b \cdot \cos h) \cdot \frac{\cos h-\cos h_{s}}{\operatorname{sen} h_{s}-h_{s} \cdot \cos h_{s}} \\
a=0.4090+0.5016 \sin \left(h_{s}-1.047\right) \\
b=0.6609+0.4767 \sin \left(h_{s}-1.047\right)
\end{aligned}
$$

where the angles are expressed in radians.

The direct hourly radiation is obtained, at every hour of the interval, as the difference of the hourly global radiation and the hourly diffuse radiation.

$$
H_{k, b}=H_{k, \Delta}-H_{k, d}
$$

From the direct and diffuse components of the solar radiation, the incident radiation on the dam faces can be computed as a sum of their hourly direct, diffuse and reflected components.

The direct component $\left(\mathrm{I}_{\mathrm{h}, \mathrm{b}}\right)$ is expressed by the relation 


$$
I_{k, b}=R_{b} \cdot H_{k, b}
$$

where the factor $R_{b}$ is given by the ratio between the cosine of the incident angle of the sunbeam and the cosine of the zenith angle.

$$
R_{b}=\frac{\cos \theta}{\cos \psi}
$$

where

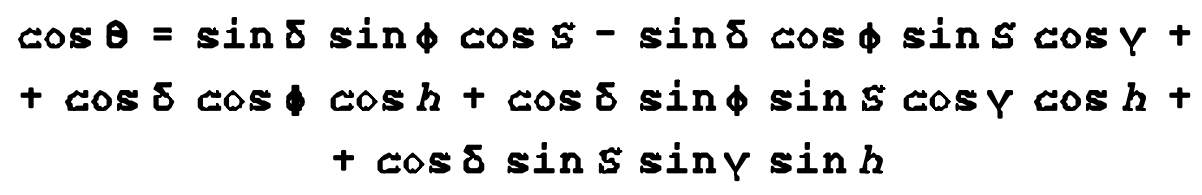

\section{$\cos \Psi=\sin \phi \sin \delta+\cos \phi \cos \delta \cos h$}

The incident angle (2) depends on the solar declination $(*)$, the latitude $(\mathrm{N})$, the hourly angle $(\mathrm{h})$, the inclination of the dam face (S) and the azimuth of the surface (( ); the zenith angle depends on the solar declination $(*)$, the latitude $(\mathrm{N})$ and the hourly angle $(\mathrm{h})$.

The diffuse component on the dam face is evaluated as

$$
I_{h, d}=\frac{(1+\cos 5)}{2} \cdot H_{h, d}
$$

The reflected component on the face can be evaluated as a fraction of the global radiation incident on the horizontal plane.

$$
I_{k, \pm}=p \cdot\left(\frac{1-\cos S}{2}\right) \cdot\left(H_{i, a}+H_{k, d}\right)
$$

In this expression $\mathrm{p}$ represents an average coefficient of reflectionfrom the surroundings of the inclined surface. In table 2 the typical values of the coefficient of reflection for different surroundings are presented 
(Coronas et al., 1982).

The sum of the direct, diffuse and reflected hourly radiation gives the total solar radiation that is incident every hour.

$$
I_{k}=I_{k, b}+I_{k, d}+I_{k, x}
$$

The daily total of the incident radiation on the dam face is obtained as the sum, from sunrise to sunset, of radiation at different times during the corresponding interval of sunshine.

\begin{tabular}{|l|c|}
\hline \multicolumn{1}{|c|}{ Type of surrounding } & $\mathrm{p}$ \\
\hline Recent snow & $80-90 \%$ \\
Old snow & $60-70 \%$ \\
Cultivated ground & \\
- Without vegetation & $10-15 \%$ \\
- Dry grass & $28-32 \%$ \\
- Lawn and wooded & $15-30 \%$ \\
Sandy soil & $15-25 \%$ \\
Cement, concrete & $55 \%$ \\
White sand & $25-40 \%$ \\
Water & \\
- Summer & $5 \%$ \\
- Winter & $18 \%$ \\
\hline \hline
\end{tabular}

Table 2.- Reflection coefficient of the surrounding

Therefore, through the present procedure, with a specific $\mathrm{H}_{0}$, the global incident radiation (I) can be determined for any given day of the year $(*)$ and any hour of the day (h), as a function of the characteristics of the location of the dam $(\mathrm{N})$, its geometry ( $\mathrm{S},(\mathrm{)})$ and its surroundings (p).

\section{2.- Ambient temperature}


In order to mathematically model the temperature variation during the day, a bi-sinusoidal function was adopted (Fig. 2).

Fig. 2.- Function for the environmental temperature

This function is expressed analytically as:

(1)

$$
T=A \cdot \sin \left(2 \pi \cdot \frac{t-b_{1}}{2 b_{2}}\right)+B
$$

(2)

$$
T=A \cdot \sin \left[2 \pi \cdot \frac{t+12-b_{1}-b_{2}}{2\left(24-b_{2}\right)}\right]+B
$$

in which,

$$
A=\frac{T_{\text {max }}-T_{\text {min }}}{2}
$$

$$
B=\frac{T_{\text {max }}+T_{\text {min }}}{2}
$$

$$
b_{1}=\frac{h_{\text {max }}+h_{\text {min }}}{2}
$$

$$
b_{2}=h_{\text {max }}+h_{\text {min }}
$$

In the preceding expressions $\mathrm{T}_{\max }$ and $\mathrm{T}_{\min }$ represent, respectively, the maximum and minimum daily temperatures, while $\mathrm{h}_{\max }$ and $\mathrm{h}_{\min }$ are the times corresponding to these temperatures, respectively.

\section{3.- Water temperature in the reservoir}


The proposed modelconsiders the thermal action of the water as a boundary condition imposed on the wet upstream face of the dam correspondtly at full reservoir. This condition is established by taking the temperature of the concrete at the dam face as the water temperature at that point, expressed by the monthly average.

This procedure permits the representation of the different temperatures at various depths. Also, in relation to the time analysis, it reflects the seasonal and annual variations of temperature, through the monthly averages.

\section{4.- Coefficients of heat transfer}

The coefficient of the heat transfer by radiation, $h_{\mathrm{r}}$, is evaluated at every instant as a function of the temperature of the environment and the surfaces, and of the Stefan-Boltzmann constant as in the Equation (8). Therefore, its implementation can be achieved through parameters that already have been analyzed.

The coefficient of heat transfer by convection, $h_{c}$, is treated as input data for the analysis, with the option that it can vary throughout the year. This coefficient, which depends on many factors, is a function primarily of the wind velocity and can be related to it empirically as proposed by several authors. In this work, the formula of Kehlbeck (1975) is utilized, as in other related works [Mirambell (1987)].

$$
h_{e}=3.83 v+4.67
$$

In this relation, $v$ is the velocity of the wind expressed in $\mathrm{m} / \mathrm{sec}$. and $\mathrm{h}_{\mathrm{c}}$ in watts $/ \mathrm{m}^{2}{ }^{\circ} \mathrm{C}$.

Consequently, the determination of the coefficient of heat transfer by convection proposed in this model is realized through the wind velocity at the dam site, which permits the analysis of its influence on the thermal behavior of the dam.

Other aspects of the numerical analysis can be found in Agulló (1991).

\section{5.- COMPARISON WITH EXPERIMENTAL DATA}

The temperatures theoretically obtained from the model have been compared with the actual temperatures registered during the monitoring of several dams in Spain that are currently being utilized. 
These dams are located in geographically different sites and are of different structural types. Table 3 presents some of their characteristics, as well as the number of thermometers used in the comparison. 


\begin{tabular}{|c|l|c|c|c||}
\hline \hline DAM & TYPE & $\begin{array}{c}\text { HEIGHT } \\
(\mathrm{m})\end{array}$ & $\begin{array}{c}\text { VOLUME } \\
\left(10^{3} \mathrm{~m}^{3}\right)\end{array}$ & $\begin{array}{c}\text { No. of } \\
\text { THERMOMETERS }\end{array}$ \\
\hline Baserca & Arch dam & 86 & 225 & 11 \\
LLauset & Arch dam & 82 & 227 & 7 \\
Almendra & Arch dam & 202 & 2186 & 12 \\
Mequinenza & Gravity dam & 81 & 1100 & 10 \\
\hline \hline
\end{tabular}

Table 3.- Dams used in the comparison with experimental data

The comparison was made between the annual temperature distributions obtained fromthe modeland actual measurements using a total of 40 thermometers. The measurements were made at the central transverse cross-section of the dam, at different heights within the cross-section and at different positions along the same height (i.e., near the upstream and downstream faces, and in the central part of the thickness).

Figures 3-5 show the graphical comparison between the annual evolution of temperature predicted by the model and the experimental values obtained from the thermometers situated in the dam, for the duration when the data were available. The cases plotted represent typical data from different thermometer locations.

Figure 3 shows the temperature evolution corresponding to one thermometer(T-48) located $1 \mathrm{mfrom}$ the upstream face and another (T-64) located $1 \mathrm{~m}$ from the downstream face of the Baserca dam.

Fig.3.- Annual temperature evolutions in the Baserca dam.

Figure 4 shows the annual temperature evolution corresponding to a thermometer (T-41) located at the center of a $12.5 \mathrm{~m}$ section in the LLauset dam. In Figure 5, which corresponds to a thermometer (A-82) located at the downstream face of the Almendra dam, the theoretical results are compared with actual measurements both for day and night time temperature evolution. 
Fig.4.- Annual evolution of temperature in the LLauset dam

Fig.5.- Annual evolution of temperature in the Almendra dam

\section{6.- CONCLUSIONS}

A simple and computationally efficient numerical model for the thermal analysis of dams is presented.

The incorporation of the climatic and environmental variables in the numerical analysis permits the satisfactory simulation of the thermal behavior of dams due to environmental actions.

The results obtained demonstrate that the proposed model predicts the evolution of temperature adequately at different zones of the dam, such as near the upstream and downstream faces, on the downstream face, and at the mid-thicknesses. Similarly, the model reflects the thermal inertia of the concrete which is apparent during the periods of phase lag between the extreme values of temperature in the environment and in the concrete of the dam.

\section{7.- ACKNOWLEDGEMENTS}

The authors are grateful to the Dirección General de Investigación Científica y Técnica (DGICYT-PB 90/0611) and the electric companies, National Hidroeléctrica of Ribagorzana, Iberduero, Hidroeléctrica Española and Hidroeléctrica of Cataluña, and to the Confederacion Hidrografica of Duero for their generous support in providing all the temperature measurements for the dams studied here.

\section{8.- REFERENCES}

- ACI (1987)

"Mass Concrete". ACI Committee 207. ACI 207.1R-87.

- AGULLO, L. (1991)

"Estudio térmico en presas de hormigón frente a la acción térmica ambiental". Tesis Doctoral. Universitat Politècnica de Catalunya. Barcelona. Junio. 
- CORONAS, A., LLORENS, M., VILLARRUBIA, M.(1982)

"Energia solar a Catalunya: Radiació solar i insolació". Publicacions i Edicions Universitat de Barcelona. Conselleria d'Indústria i Energia. Generalitat de Catalunya. Barcelona.

- DUFFIE, J.A., BECKMAN, W.A. (1974)

"Solar Energy Thermal Processes". Wiley Interscience. New York.

- KEHLBECK, F. (1978)

"Einfluss der Sonnenstrahlung bei Brückenbauwerken". (Effect of solar Radiation on Bridge Structures). Werner-Verlag. Düsseldorf.

- LIU, B., JORDAN, R.C. (1963)

"The Long-Term Average Performance of Flat-Plate Solar Energy Collectors". Solar Energy, Vol. 7.

- LIU, B., JORDAN, R.C. (1967)

"Low Temperature Engieneering Applications of Solar Energy". ASURAE. New York.

- MIRAMBELL, E. (1987)

"Criterios de diseño en puentes de hormigón frente a la acción térmica ambiental". Tesis Doctoral. Universitat Politècnica de Catalunya. Barcelona. Enero.

- STUCKY, A., DERRON, M. (1957)

"Problèmes thermiques posès par la construction des barrages-réservoires". École Polytechnique de l'Université de Lausanne. Publicatión $n^{\circ} 38$. Sciencies et Technique. Lausanne.

- TOWNSEND, C.L. (1965)

"Control of Craking in Mass Concrete Structures". Bureau of Recamation. United States Deparment of the Interior. Washington.

- ZIENKIEWICZ, O.C. (1980)

"El método de los elementos finitos". Editorial Reverté, S.A. España. 


\section{LIST OF FIGURES}

FIG. 1.- MODEL OF THE ANALYSIS OF THE TRANSVERSAL SECTION FIG. 2.- FUNCTION FOR THE ENVIRONMENTAL TEMPERATURE FIG. 3.- ANNUAL TEMPERATURE EVOLUTIONS IN THE BASERCA DAM FIG. 4.- ANNUAL EVOLUTION OF TEMPERATURE IN THE LLAUSET DAM FIG. 5.- ANNUAL EVOLUTION OF TEMPERATURE IN THE ALMENDRA DAM

\section{LIST OF TABLES}

TABLE 1.- MIDDLE DAYS AND THEIR SOLAR DECLINATION TABLE 2.- REFLECTION COEFFICIENT OF THE SURROUNDING TABLE 3.- DAMS USED IN THE COMPARISON WHIT EXPERIMENTAL DATA 